\title{
Politics Without "Brainwashing": A Philosophical Defence of Social Justice Education
}

\author{
LAUREN BIALYSTOK
}

Ontario Institute for Studies in Education

University of Toronto

Toronto, Ontario, Canada

\begin{abstract}
Social justice education (SJE) is a ubiquitous, if inconsistently defined, component of contemporary education theory and practice. Recently, SJE has come under fire for being politically biased and even "brainwashing" children in the public education system. In a liberal democracy such as our own, it is important that statesponsored actions and essential public goods can be justified to all citizens, not only to those with a particular set of beliefs. To defend SJE against its detractors, therefore, it is insufficient to argue over the concrete values that SJE seeks to inculcate; it is instead necessary to develop a philosophical argument situating SJE within a conception of democratic liberalism. This article provides such an argument by reviewing competing conceptions of liberalism, analyzing the political culture in Canada, and applying an interpretation of comprehensive liberalism to specific educational initiatives. Rather than defining or justifying all instances of SJE, the goal is to show how some, but not all, substantive political views can be coherently espoused in the Canadian education system without turning into "brainwashing." Five specific criteria are offered for discriminating between legitimate and illegitimate forms of education within Canadian liberalism. I use these criteria to show that much of what we recognize as SJE is justifiable, not because every citizen endorses the concrete values it represents, but because and only insofar as it reflects a democratic political culture that does.
\end{abstract}

\section{ARE SCHOOLS "BRAINWASHING OUR CHILDREN"?}

A recent cover story in the popular Canadian general interest magazine, Maclean's, proclaimed that social justice education in Canada has evolved from a nonpartisan emphasis on tolerance to political "brainwashing" (Reynolds, 2012). Stories of young students being encouraged to protest big oil, "explore their sexuality," and criticize the World Trade Organization raise the concern that "social justice" is a moniker concealing a variety of practices intended to recruit young students to progressive causes. While

\footnotetext{
(C) 2014 by The Ontario Institute for Studies in Education of the University of Toronto

Curriculum Inquiry 44:3 (2014)

Published by Wiley Periodicals, Inc., 350 Main Street, Malden, MA 02148, USA, and 9600 Garsington Road,

Oxford OX4 2DQ, UK

doi: $10.1111 /$ curi.12047
} 
Canadian schools and teachers have a mandate to emphasize inclusiveness and anti-oppression (e.g., Ontario Ministry of Education, 2009), it is not always clear when that mandate is exceeded by teachers with political agendas. Increasingly, the scope and application of some educational activities and policies are associated with substantive policy positions that can be easily lined up with the political left-of-centre. Indeed, politicians are beginning to express concern over the ideological bent in public education. The Maclean's article notes that the third graders' oil pipeline protest elicited fury from PC MPP Rob Milligan, who called the teacher's activity "brainwashing" and "an abuse of power" (Reynolds, 2012, p. 22). ${ }^{2}$

In an educational climate in which "social justice education" (SJE) is a ubiquitous phrase and increasingly emphasized in the preparation of new teachers, it is reasonable to expect critical assessment of what we mean by SJE and why it matters. Educational scholars debate the contours of the concept regularly (e.g., Bull, 2008, 2009; Carlisle, Jackson, \& George, 2006; Gewirtz, 2006; Hackman, 2005; Sensoy \& DiAngelo, 2012; Zajda, Majhanovich, \& Rust, 2006) but these discourses are typically internal, directed toward sympathetic colleagues, not toward average parents and politicians. As the Maclean's article demonstrates, SJE does not always have positive connotations. The recent outrage over politicised school activities seems to warrant a more explicit defence of these practices. Although public opinion about academic matters rarely if ever gets a vote in how education is theorized and practised, the political stakes of engaging in SJE in neoliberal times are not to be underestimated. If we truly value SJE and think it belongs in mandatory education, we need to defend it beyond the educational community: it needs to reflect public values and command respect in the communities where it takes place. Even if such a defence should not be necessary in an ideal world, it is instrumentally necessary to ensure there is enough political will to continue endorsing policies that facilitate and protect this work.

The kind of defence that SJE calls out for is philosophical. ${ }^{3}$ Questions of justice themselves are philosophical, usually addressed in moral and political philosophy. What is the most just way of distributing scarce resources? How do we ensure that people of different abilities have equal opportunities? Why should we even assume that equal opportunity is just? But beyond all of this, the issue of whether particular conceptions of justice belong in public education systems is also a vexing philosophical question. Who should decide what is taught in public schools? Whence does their authority come? Is it teachers' job (or right) to impose their own conceptions of justice on their students?

These questions have been turned over by philosophers, including educational philosophers, for decades (Callan, 1997; Gutmann, 1987; McDonough \& Feinberg, 2003; Warnick, 2012). This thinking now needs to be applied concretely to the political backlash against SJE in Canada in particular. ${ }^{4}$ In a liberal democratic society such as our own, citizens have a 
legitimate interest in knowing that public institutions such as the education system reflect values that everyone can sign on to, or are at least derived from procedures that enjoy public approval. If something taught in public schools is perceived as a form of "brainwashing," it is a challenge not only to the individual teachers or administrators involved, but also to the integrity of the system that claims to deliver an essential public good. A deeper understanding and critique of public goods and public values in the Canadian context needs to be leveraged to respond to allegations of brainwashing, as well as to reinforce objections to actual instances of inappropriate education or indoctrination.

In this article I offer an outline for the type of philosophical defence that could be deployed in the face of challenges to SJE. I am not interested in policing the use of the term, but rather in providing a refutation of the charge that SJE never has a place in Canadian schools. In so doing I will argue for parameters within which educators may teach substantive political views, whether the political content is ostensibly aimed at social justice or not. ${ }^{5}$ There are four sections to this argument. First, I review the plurality of conceptions of SJE and show why it is an inherently controversial concept that invites the kind of pushback that is chronicled in Maclean's. Second, I explain the basic elements of liberal statehood that have come to inform our public institutions and defend a more robust version of liberalism, known as "comprehensive liberalism." Third, I argue that many practices that we wish to protect under the banner of SJE can be defended by appeal to Canada's documented commitments to substantive values of equality and individual rights, even when some politicians and citizens disagree with them. Finally, I suggest five initial ${ }^{6}$ criteria for distinguishing between defensible SJE and "brainwashing." Namely, any political views forwarded in K-12 education in Canada must

1) have legislative backing in the form of such precedents as the Charter, human rights codes, and current policy;

2) be compatible with reasonable pluralism;

3) not engage in partisan politics or political activism that students do not choose,

4) be connected with developing skills for democratic engagement; and

5) respect students' freedom to abstain from activities that contravene their own (emerging or tentative) comprehensive doctrines.

Before concluding the article I will demonstrate how these criteria would be applied to some contentious cases mentioned in Maclean's.

\section{SOCIAL JUSTICE, SJE, AND THE BACKLASH}

In the last couple of decades, educational institutions in North America have become more explicit about their commitments to social justice in all 
aspects of their operations, including the design of classrooms and schools, the content of curriculum, curricular accoutrements such as school events and clubs, and pedagogy itself (Ukpokodu, 2010). Many faculties of education highlight social justice in their approach to preparing pre-service teachers for their work and teacher candidates frequently reference social justice ideas when describing their roles and aspirations as teachers. The University of Windsor hosts an annual social justice in education conference. Scholarship about SJE and its many components and variations continues to grow in educational publications, and since 2006 a periodical, Education, Citizenship and Social Justice, has been dedicated to the topic. Social justice is available as a concentration in many faculties of education across North America, and my own department at the Ontario Institute for Studies in Education, the largest education faculty in Canada, has SJE in its title.

Among many educators and educational researchers, SJE has become not only ubiquitous but also almost untouchable, the apple pie of contemporary education work. This is true despite the great plurality of definitions of SJE among educators. However, from the outside, SJE may appear as more uniform and less unimpeachable. In both Canada and the United States conservative political and institutional forces have collided with the tide of SJE and sought to stem its momentum. In 2006, the National Council for Accreditation of Teacher Education notoriously removed "social justice" from all its documents. During the accreditation hearing, the president Arthur E. Wise (2006) said the following:

I have come to learn, painfully over the last year, the term is susceptible to a variety of definitions. ... [M] ore recently the phrase has acquired some new meanings, evidently connected to a radical social agenda. So lest there be any misunderstanding about our intentions in this regard, we have decided to remove this phrase totally from our vocabulary. (p. 255)

In Canada, educational movements that are perceived to embody a "radical" version of social justice have also been quelled. In Ontario in 2010, an updated sex education curriculum that would have familiarized Grade 3 students with different sexual orientations and family types was buried almost as soon as it was introduced because of political and religious protests. In 2009, Alberta passed Bill 44, which requires parents to receive written notification when human sexuality, sexual orientation, or religion are going to be raised in class and grants them the right to remove their children from school if they disapprove of the material being taught. ${ }^{7}$

More generally, across North America, the rise of neoliberal policies in education has constituted an implicit if not explicit challenge to SJE. Fuelled by views that are both politically and educationally conservative, neoliberalism emphasizes high-stakes standardized testing, increasing privatization and commercialization in the education system, and assaults 
on subject areas and teaching methods that are seen as superfluous or radical (Apple, 2009; Grimaldi, 2012; Saltman, 2006). Not only do these policies make it difficult for resource-strapped teachers to address such topics as social inequality, but the policies themselves, such as No Child Left Behind in the United States, exacerbate social inequality and may reinforce the kinds of prejudices that SJE often aims to debunk (Lipman, 2007). The movement among teachers, teacher educators and researchers to enhance SJE seems to be nearly coincident with the obstruction of SJE at higher levels of governance.

It is not surprising that a feel-good phrase like "social justice" should spark such controversy. The term is ethically loaded, even outside the context of education. To borrow a coinage from Charles Stevenson, the late philosopher of language, it is an "emotive" phrase, meaning that it cannot be uttered without any evaluative component— to say that something is socially just is to recommend it. ${ }^{8}$ No one proudly opposes "social justice." The battle is only in the definition: everyone wants to claim it for their own.

At the same time, identifying a need for social justice, and especially SJE, is an inherently oppositional stance: it implies that there is something that needs rectifying or improving; it criticizes the status quo. ${ }^{9}$ This may put political and educational leaders in an uncomfortably defensive position. While they, too, would like to endorse social justice (on some conception), they are responsible in part for the status quo. This gives them a prima facie reason to be wary of social justice critics. Hence conservatism, which is usually understood as an ideology that resists social change, is often juxtaposed with social justice-even though the neoliberal variety of conservatism that currently holds much sway is welcome to many types of change (privatization of social services, curbs on immigration, etc.), and social justice has strong roots in some of the most conservative institutions, such as Christianity (Zajda et al., 2006). The very existence of a powerful SJE movement thus poses a certain challenge to people in power before any demands have even been articulated, and regardless of which political party is in office.

So the tug-of-war over SJE is hard to resolve in part because it represents an inescapable conflict between change and the status quo, and in part because of substantive political positions that have become associated with each side. Defending SJE requires transcending the power struggle it gives rise to and looking more carefully at the meaning of SJE and its compatibility with Canadian values.

A brief overview of recent publications in education will verify the plurality of definitions of SJE at work in academia and teacher practice. Hackman (2005) identifies "five essential components for SJE": they are "content mastery," "critical thinking and the analysis of oppression," "action and social change," "personal reflection," and "awareness of multicultural group dynamics." 10 Notice that these encompass both formal components of teaching as well as specific content and values. Hytten and 
Bettez (2011) review dozens of definitions and conceptions of SJE in the literature, including "full and equal participation of all groups in a society that is mutually shaped to meet their needs" (Bell, 1997, p. 3) and "a disposition toward recognizing and eradicating all forms of oppression and differential treatment" (Murrell, 2006, p. 81). They further classify accounts of SJE into five categories: (1) philosophical/conceptual, which draw on philosophical literature and methods to achieve greater clarity about the nature of justice; (2) practical, which delineate "conditions or competencies" that provide benchmarks for educators seeking to practice SJE (Hytten \& Bettez, 2011, p. 12); (3) ethnographic/narrative, which are studies of systemic and institutionally reinforced inequalities based on race, identity, etc., such as Kozol's (2005) The Shame of the Nation; (4) theoretically specific, which are accounts "connected to specific leftist and/or radical movements within academia" such as whiteness studies, multiculturalism, and queer theory (Hytten \& Bettez, 2011, p. 16); and (5) democratically grounded, which "situate their thinking about justice in connection to considering the fundamental purposes of education in a democratic society" (Hytten \& Bettez, 2011, p. 19).

This taxonomy is a very helpful guide through a sea of literature that contributes, in different ways and under different names, to a collective understanding of SJE. Indeed, there is no single concept of SJE but rather a constellation of discursive and pedagogical practices that emerge from various intellectual and political traditions. This suggests that the general enthusiasm for SJE among many educators and educational scholars uses a very broad net to characterize its commitments-perhaps too broad to admit of important distinctions. Moreover, it illustrates the politically significant fact that whether a particular educational activity falls under SJE, and whether it deserves a principled defence, depends very much on who is defining the term.

A lack of consensus about the meaning of SJE is not in itself a problem; the term is far too nebulous and versatile to be captured by any one definition, and scholarly pluralism can be a virtue. There are commonalities across definitions and practical applications, however: SJE as it is currently understood refers to values that are broadly recognized as "progressive." It takes up to various degrees the goals of anti-oppression politics, anti-colonialism, environmentalism, and a critique of corporate globalization, with more or less overt sympathy for the social welfare state and resistance to educational policies characteristic of neoliberalism. It tends to depend on or endorse a robust notion of democracy and sees education as an indispensable site of social and political participation.

These broad substantive values behind SJE can be expressed and taught in many different ways. Indoctrination is not only a matter of what is taught, but perhaps more to the point, how something is taught. We should not assume that all conceptions or applications of SJE are equally valid and defensible in a liberal democracy. Indeed, the Maclean's article 
and many of the objectors it cites seem to pick on the most sensational examples of alleged SJE. Here are two examples: "In Laval, Que., a sixyear-old boy was disqualified from a teddy-bear contest because a Ziploc was found in his lunch instead of a reusable container. In Ste-Marie-deKent, N.B., in 2009, Grade 4 students were given 10 minutes to decide which three people from this group should be saved from an imminent planetary explosion: a black African, a Chinese person, an Aboriginal, an Acadian francophone and an Anglophone" (Reynolds, 2012, p. 20). The first example, insofar as it can be associated with SJE as a call to environmental consciousness, is obviously an extreme example with questionable educational merit. The second example, a classroom activity that may have been taken bizarrely out of context, seems to caricature the discourse of equity without encouraging social justice on any conception-for why should there be a just defence for saving one individual over four others on the basis of their ethnic identity alone? (If anything, this experiment is anti-equity.)

These examples show that our efforts should not be focused on defending any practices that anyone has ever described as SJE, but rather on establishing principles for politically defensible educational practices in general. We can then assess whether individual practices are legitimate regardless of which definition of SJE is being employed. I will argue that educational activities can take stances on controversial political issues as long as they cohere with contemporary Canadian liberalism, and that much of the work usually defined as SJE can live up to this condition. In fact, much of what can be defined as SJE reinforces Canadian political values and should be welcomed for it.

\section{LIBERALISM, JUSTICE AND EDUCATION}

Liberalism is the political philosophical tradition, dating to early Western modernity, that continues to inform most of our social and political organization in North America today. Historically intertwined with democracy, liberalism is broadly equivalent to the principle that individuals should be free to pursue the life they want, complete with whichever beliefs, values and goals they deem to be correct, as long as they do not thereby infringe on the ability of others to do the same. The liberal state earns its legitimacy by acting in accordance with value pluralism rather than imposing any particular values on citizens. Moreover, when the state must make decisions that cannot please everybody, it should aim to do so by recourse to reasons that everyone can in principle respect. ${ }^{11}$ This means that even if I disagree with a particular state policy or find that it disadvantages me personally, I should be able to recognize impartial reasons in support of it. Despite extensive debate about the proper meaning and scope of liberalism (Dworkin, 1978; Gaus, 2003, 2004; Rawls, 1993), as well as challenges to its 
philosophical monopoly on Western societies (Sandel, 1998); Taylor, 2003), liberalism in some form continues to describe Canadian political culture to an unrivalled degree.

The backdrop of liberalism provides both the explanation for why challenges to SJE need to be taken seriously as well as the framework through which they need to be addressed. Jeremy Waldron (1987) says that what unites different forms of liberalism is "a certain view about the justification of social arrangements" (p. 128). Specifically, in contrast to political arrangements such as military regimes, in a liberal society "all aspects of the social should either be made acceptable or be capable of being made acceptable to every last individual" (Waldron, 1987, p. 128). ${ }^{12}$ This means that if state-sponsored actions such as public education measures are theoretically unacceptable to some group of otherwise reasonable ${ }^{13}$ citizens, it should be a cause of concern not just for that group, but for all citizens. Defenders of SJE cannot shout down the SJE protestors simply because they agree with the content of SJE and think their opponents are mistaken. While there will never be perfect agreement with every policy the government implements, the liberal vision is of assent to a background set of values or procedures that can be accepted even when they result in policies that citizens disagree with.

"Overlapping consensus" is Rawls's phrase referring to this background, or the common principles that people with different beliefs can share. The content of the overlapping consensus is a "political conception," that is, a view about the basic structure of society that is not dependent on any particular conception of the good (Rawls, 1993, p. 134). Rawls argues that numerous different belief systems can provide internal reasons to endorse the content of the overlapping consensus.

However the degree to which such "overlapping consensus" can realistically be secured in a pluralistic society is contested among liberals. To be somewhat binary, the views can be divided into political liberalism and comprehensive liberalism, both of which are arguably embodied (if not simultaneously) by John Rawls. ${ }^{14}$ On the one hand, there are political liberals, famously galvanized by Rawls (1993) in Political Liberalism, who hold out hope that we can agree on a "purely political conception of justice" that avoids trampling on anyone's individual views about what is just, good, or true in other domains. This requires that political arrangements cannot be logically dependent on adherence to any "comprehensive doctrines" about what makes for a good life or a good citizen; they are "freestanding" (Rawls, 1993, p. 12). A "comprehensive doctrine" in this sense is an account of how the world is, what makes for a good life, or something of that nature. Religious doctrines and major philosophical schools of thought count as comprehensive doctrines. Yet the term comprehensive is certainly misleading here, because even very partial and nondogmatic theories are unavailable as the basis of political arrangements, according to political liberalism, as long as there is disagreement over 
them. Political arrangements should be ones that anybody would reasonably endorse to ensure their own ability to pursue the good life as they see it (Rawls, 1985, 1993).

On the political liberal conception, the government is to remain neutral on any matters that are not directly pertinent to political arrangements. This would include unresolvable, contentious issues, such as the existence of God, or the ethics of eating animals. "Neutral" means that the state should neither take a stance on nor give preference to those who take particular stances on such matters. ${ }^{15}$ So instead of favouring atheism, vegetarianism, or other positions, the state endorses the meta-view that everyone is entitled to think what they want about these substantive matters, as long as they display the appropriate political virtues. ${ }^{16}$

On the other hand, there are liberals who are sceptical about separating political matters from all other kinds of controversial judgments. They believe that liberalism is itself a kind of view about how the world is and what makes for a good life, albeit one that is characterized by its respect for other views (Berlin, 1969; Raz, 1986). In other words, they think that the political conception does logically depend on a comprehensive doctrine of some sort, and is not likely to be the subject of overlapping consensus. This view, known as comprehensive liberalism, "affirms liberal political arrangements in the name of certain moral ideals, such as autonomy, individuality or self-reliance" (Sandel, 1998, p. 189). The moral ideals behind comprehensive liberalism do not themselves need to be comprehensive systematic theories, such as religious doctrines. As Callan (1997) explains, "nothing in the concept of comprehensive liberalism entails a commitment to an allpurpose criterion of right and wrong such as utilitarianism or a grand epistemological theory such as pragmatism" (p. 17). The crucial departure from political liberalism here is that there is no "purely political" or "freestanding" conception that all reasonable people will assent to, irrespective of what else they believe. Even people interested in fair terms of social cooperation will disagree about political procedures. At least in this respect, therefore, comprehensive liberalism is not neutral in aim: individuals who decline to sign on to certain substantive values will not necessarily agree with liberal political arrangements, and may find their views disfavoured. ${ }^{17}$

Rawls (1993) argues that comprehensive liberalism actually collapses under its own logic. Because the substantive views taken will necessarily exclude some reasonable others who hold incompatible views, comprehensive liberalism justifies policies that are inimical to true pluralism and thereby ceases to be liberal at all. Critics respond by questioning the definition of "reasonable" at work in Rawls's system, which is already exclusive. A comprehensive doctrine has to be "reasonable"- that is, amenable to being controlled by liberal principles-in order to find protection among fellow comprehensive doctrines. But how is this standard of "reasonableness" decided, if not by recourse to another comprehensive 
doctrine? And what ought liberals to do with the persistent believers in "unreasonable" political doctrines, such as extremists, terrorists, and fundamentalists?

If a citizen with politically liberal beliefs (regardless of her other beliefs) is defined as "reasonable," and if only "reasonable citizens" ought to have their views about political justice taken seriously in public, ${ }^{18}$ then what we are dealing with is not "consensus" in general but a circumscribed form of consensus, one that can only flourish among people who have met preexisting standards of reasonableness. ${ }^{19}$ Illiberal views may be "tolerated" in a liberal society but they cannot expect the same standard of state justification as liberal views (Callan, 1997, pp. 22-23). This may translate into policies and political practices in various ways. For example, not all religions may receive entirely equal protection for all their beliefs. Insofar as religious beliefs are aggressively illiberal and call for the abrogation of others' rights, they are insufficiently "reasonable" to be included in the umbrella of liberal pluralism (Callan, 1997, p. 25; Rawls, 1993, p. 55). Hence liberal states tend to be criticized for having a secular bias and a bias in favour of Western Enlightenment-style "reason" and individualism, among other things (Mouffe, 2000; Wolterstorff, 1997). As Callan (1997) explains, "the problem of inclusion is as much about filtering out various moral toxins that threaten to contaminate public reason as it is about honouring the differences that we ought to honour" (p. 22). This is not to suggest that "unreasonable" doctrines, and unreasonable citizens, should dictate the terms of political process in a liberal society. They should not: and this is precisely why liberalism is at least partially a comprehensive doctrine.

Defenders of political liberalism sometimes insist that the credentials for inclusion in political debate are extremely minimal, so much so that there is no reason to expect any serious controversy over them. Nussbaum (2011) acknowledges that this view has "definite moral content and is justified by some definite moral values; nonetheless, it is sufficiently abstemious . . . to avoid controversial ideas of the type that divide citizens who reasonably disagree" (p. 16). Larmore (1990) only asks for "the norms of rational dialogue and equal respect," without which any orderly political culture is virtually unthinkable (p. 353). Arguably this is all that is meant by "reasonable," and those who are unreasonable by these standards are manifestly uninterested in cooperating with their fellow citizens at all. Pluralism can thrive and the state can be based on uncontroversial values so long as everyone is interested in stability.

Yet even a very basic, formal requirement for political life such as "equal respect" is not uncontroversial in its application. Consider debates over the protection of same-sex couples in law. Clearly there are those who oppose such measures, but this is not concerning to the liberal; the question is whether the opponents would challenge the principle of "equal respect" that it seeks to instantiate. This is less obvious than it may look. What, 
exactly, does respect for persons amount to? Is the Catholic doctrine of "love the sinner, hate the sin" an embodiment of such respect? I strongly doubt that non-heterosexuals who have been raised in Catholic institutions would think so. Disagreement at the level of policy, therefore, often cuts right to disagreement at the level of political principles.

This is because political principles themselves require input from supposedly non-political moral views to be adjudicated. Sandel makes this argument particularly eloquently with the example of abortion. The liberal position on abortion is strictly political in the sense that it attempts to secure individual rights and refrain from pronouncing on the morality of abortion. But the strictly political approach to abortion is only possible given a moral stance on the act of abortion: "The more confident we are that fetuses are, in the relevant moral sense, different from babies, the more confident we can be in affirming a political conception of justice that sets aside the controversy about the moral status of fetuses ... the case for abortion rights cannot be neutral with respect to that moral and religious controversy. It must engage with rather than avoid the comprehensive moral and religious doctrines at stake" (Sandel, 1998, p. 198).

When push comes to shove, neutrality-even the modest version, neutrality of aim-is at best an elusive ideal. There is no way for the liberal state to always remain neutral on important questions that divide reasonable citizens of different persuasions. Yet it remains "liberal" by favouring those positions that are most conducive to respect for pluralism and individual rights, sometimes carving out a more substantial role for the government in advancing and protecting these values. ${ }^{20}$ This, I claim in the next section, is what Canada has done.

This brief overview of the poles in liberal thought allows us to enter the debate about SJE and political education more productively. It should be clear that the interpretation of liberalism we favour will influence our assessment of what kind of teaching is permissible in primary and secondary schools, and also that both categories of liberalism entail puzzles about how to appropriately educate children in a pluralistic society. Although it may look as though political liberalism is the most natural way of deflecting the brainwashing objection, it is inadequate because education is never neutral, even if state neutrality were possible. In the remainder of this section I will explain these arguments.

Because indoctrination is a persistent concern in the realm of education, and because it has been particularly associated with highly illiberal institutions and societies such as religious cults and fascist regimes, it may seem obvious that liberal education needs to observe neutrality. Societies such as our own are characterized precisely by the freedom to believe in things that may differ from what our parents, community, or elected officials believe. "Education" that abrogates this freedom is indefensible, particularly because children lack the experience and maturity to question what adults tell them. ${ }^{21}$ A substantive view presented as Truth in a state-sanctioned 
educational setting could easily be interpreted as universal and unassailable. Liberal education is therefore intended to furnish students with skills such as critical thinking that enable them to adjudicate substantive questions of the good for themselves instead of imposing normative views on them. Political education should likewise aim to create informed citizens rather than individuals with any particular comprehensive views: "education [should] include such things as knowledge of their constitutional and civic rights ... [and] prepare them to be fully cooperating members of society" (Rawls, 1993, p. 199). Hence, any form of education that exploits the impressionability of children by insisting on certain doctrines at the expense of others is a breach of the state's legitimate extent and impedes, rather than nurtures, the development of children into responsible citizens. Moreover, such indoctrination would infringe on the rights of parents; while the state provides common education, parents reserve the more substantive right to inculcate children into their culture, beliefs, ways of thinking, and ethical judgements (Neufeld \& Davis, 2010). It is easy to see how SJE, when perceived as partisan persuasion, threatens to collide with these basic liberal values. ${ }^{22}$

As most teachers know, however, this vision of a politically neutral education is profoundly unrealistic, if not also profoundly undesirable. First, all education is biased-from the choice of the curriculum to the organization of schools to the modes of assessment and evaluation-thus some conceptions of what is "good" or "right," beyond basic respect for pluralism, will seep into students' experiences regardless of the teacher's intentions. To be clear, these conceptions will not always be presented as select reasonable views of which there are many others: they will, at least in lower grades, be susceptible to being viewed as exclusive truths, just as opponents of indoctrination fear. Such an outcome seems unpalatable to political liberals. Second, and more troublesome for liberal debates about the proper scope of education, children need some reliable structures in which to develop intellectually and emotionally. They need candidates for what is good as well as broad ways of thinking about the world that allow them to make sense of their experiences before they can become autonomous ethical agents. ${ }^{23}$ Indeed, in the absence of this type of content, it is difficult to imagine education-especially of primary and intermediate students-occurring at all. Hence, it is not a question of how to remove any whiff of partisanship or comprehensive doctrines from education. Is the purpose of education to develop students' capacity to make autonomous judgements? Or is it to instil some comprehensive values and beliefs from which others can be later drawn? It is both: the two purposes coincide. ${ }^{24}$

Political liberalism is of limited help here, as it assumes that individuals have the ability to choose between competing conceptions of the good, while acknowledging that this is a capacity restricted to rational adults, at best. Children are by definition not yet ready to separate their own views of the world from others that are equally reasonable, whichever definition of 
the latter is preferred; in Rawls's (1993) terminology, children cannot yet assume the "burdens of judgment" (p. 54). In education, unlike in much analytic ethical theory, the rational agents who are supposed to make judgements about the good are formed precisely through interactions with particular conceptions of the good. They do not precede such judgements.

A purely formal conception of education that stays neutral on substantive issues-either by presenting them as equally reasonable or avoiding them altogether-is thus impossible. So the question becomes, how does education remain "liberal" and pluralistic while inevitably favouring certain worldviews over others? And how can the emphasis on these views be defended to parents and politicians who disagree with them? In the remainder of this article I attempt to sketch out answers to these questions.

\section{A PHILOSOPHICAL DEFENCE OF SJE}

However it is defined and implemented, a defence of SJE that takes seriously the concerns about indoctrination in a liberal democracy can proceed in one of two broad directions. It could either argue that SJE is bound within a strictly political conception of liberalism and only endorses positions on which there is no "reasonable" controversy; or it could bite the bullet and acknowledge that it is making claims about the good that are not always subject to overlapping consensus, but are nevertheless justified. If the second route is taken, the account will also need to show why the substantive claims associated with SJE, but not any substantive claims whatsoever, are justified in the education system of a liberal democracy. This is critical: If a teacher can preach environmentalism and deny the selfregulation of the economy, why cannot a Jim Keegstra preach antiSemitism and deny the Holocaust? ${ }^{25}$ The lines must be drawn carefully so as to be expansive but not undiscriminating.

The first option is initially attractive but ultimately succumbs to the same criticisms as political liberalism in general. Primary among these is the untenable assumption that students can be initiated into a political culture and system of cooperation without recourse to controversial views about the good-that such education is "freestanding." On a view of education as essentially the acquisition of skills and mastering of facts, it is possible, in principle, to view SJE as developing "neutral" skills such as understanding current issues, political literacy, and critical thinking. To be sure, there is an important argument to be made for mandatory civic or democratic education that includes such elements (Gutmann, 1987,1995; Rawls, 1993). Yet it is naive to hold that these exercises can be pursued with no recommendations about what students should believe, value, and choose. If nothing else, the biases of the teacher, the students, and the communities in which the school is embedded with loom large in any exploration of 
political topics. Besides, SJE itself is more than conventional civic education: it is not confined to high school civics courses ${ }^{26}$ and often explicitly attempts to foster political values beyond equal respect or rational dialogue, such as the redistribution of wealth and resources (see example 4 below).

The better option, then, is to accept that SJE depends on certain views about the good that do not enjoy overlapping consensus, and to set about the task of justifying this form of bias. We have seen that SJE is not consistently defined. It ranges from pedagogical methods to extracurricular activism, from moderate versions of multiculturalism to full-fledged affirmative action. And it can occur on a systemic level, such as through state policy, or on a micro-level, such as through particular classroom initiatives. Yet if we focus just on the political values expressed in SJE, some recurring patterns come to light. As explained above, SJE understands itself to be "progressive": it tends to endorse diversity and the equalization of opportunity; inclusive attitudes toward families, sexuality and relationships; care for the environment; attitudes that respect, but do not rely on, religious viewpoints; opposition to all forms of oppression and efforts to make them visible, especially to people with privilege; and critiquing the reach of capitalism, particularly as it interacts with democratic institutions.

While these positions may, depending on how they are taught, be aligned with partisan political perspectives, they also have some solid foundations in Canadian law and political culture. Canada has taken various positions on the organization of society for which it has rightly been recognized internationally as a mostly progressive and tolerant country. Canada's positions are not de facto right or laudable simply because they are Canadian, but many of them are available to practitioners of SJE as precedents of the views they wish to encourage. First, the basic rights of all citizens are enshrined in the Canadian Charter of Rights and Freedoms and re-enforced through provincial human rights codes. Individuals and organizations that denounce equality in the public realm are in contravention of Canadian law. Second, Canadian governments have taken on additional burdens to ensure that these rights are meaningful, despite the persistence of alternative views about the scope and nature of political justice. We not only declare that discrimination on the basis of ability is illegal, but we also take steps to actively include those who have been systemically marginalized through such legislation as the Accessibility for Ontarians with Disabilities Act (2005). We not only aspire to protect individuals from discrimination on the grounds of sex and gender identity, but we also provide state funding for sex reassignment surgery so that transgender individuals can live the lives they identify with. ${ }^{27}$ We not only speak of equal economic opportunity in vague terms, but we also have a long history of state programs to help support the unemployed and those who require greater social assistance to actualize their potential. ${ }^{28}$ These types of precedents 
point to a Canadian conception of "social justice" that goes beyond minimalist liberal credentials. They show that the basic structure of our society is already invested with certain comprehensive values; it is not "freestanding."

The liberalism we embrace today is thus considerably more robust than the bare liberalism of small government and equal protection under the law, or what McDonough and Feinberg (2003) call "classical liberalism" (pp. 4-5). Instead, "contemporary liberalism" sees the government as playing a larger role in equalizing opportunity, ensuring pluralism, and eradicating oppression (McDonough \& Feinberg, 2003). ${ }^{29}$ In so doing, the Canadian version of liberalism corresponds to a thicker slate of liberal values, wherein individual autonomy, self-actualization, and exposure to diversity are upheld as necessary ingredients of the good life.

But in case it is objected that these values can all be explained as products of some tacit political consensus, consider the stance Canada has taken on two questions of justice over which there is a decided lack of consensus. First, Canada legalized same-sex marriage in 2005, pre-empting many other jurisdictions that have since followed suit. At first blush this move is simply a logical extension of political liberalism: denying same-sex couples the right to marry is an instance of discrimination that cannot be justified by referring to the rights of other individuals or groups, hence it is structurally illiberal. As we know, however, the underlying view that the 2005 law represents-the view that same-sex relationships are as valid as heterosexual ones-remains immensely controversial, and opponents even take it as an assault on their own "way of life." Hence, the comprehensive doctrines of some Canadians are hereby enshrined in federal law, while the comprehensive doctrines of those who are morally opposed to homosexuality are explicitly undermined and rendered less "reasonable" by public standards, even if they meet other criteria for reasonableness. Second example: Canada is unique among Western states in having no law restricting access to abortion. The famous Morgentaler decision (1988) took a strong stance on an issue that has plagued liberal democracies for centuries. It reaffirmed this stance by granting Dr. Morgentaler the Order of Canada, the second-highest national honour for merit, in 2008. As with same-sex marriage, our abortion law (or lack thereof) is an example of a liberal political arrangement justified by substantive values that not everyone accepts. If this were an obvious stance for liberal governments to take, there would be less variation around the world in abortion rights and fewer legislative hurdles to widespread access to abortion. ${ }^{30}$

These examples confirm that the Canadian state and provincial authorities do not observe neutrality of aim (avoiding favouring some comprehensive views over others) or necessarily seek acceptance by all "reasonable" citizens. Some Canadians would not choose to protect as many rights as we in fact do, or they would choose to protect different ones. Some views of the good are certainly more prominent, and afforded more state protection, 
than others. Nor are these static: as Canadian culture evolves, political values evolve with it. The same-sex marriage legislation may have been unthinkable 30 years ago. Today, even leaders who may personally disagree with the worldview it reflects know better than to suggest re-opening it for public debate. If there is a neutral liberal state anywhere, Canada is not it.

Armed with this understanding of Canadian values, we are in a position to better defend at least most SJE against charges of illegitimate bias or "brainwashing." Regardless of how it is defined, most SJE hangs on the coattails of comprehensive doctrines that have been given greater support in the wider political landscape. We can say that SJE chases the progressive horizon of Canadian politics. The values expressed in defensible SJE reflect and seek to build on concrete achievements in Canadian law and political developments that help define us as a nation, and to bridge the gap between the promise of these laws and the reality for many Canadians. At its most powerful, SJE exposes the injustice in the status quo by appealing to the justice of the political ideals that we aspire to-for example, invoking the Charter to illuminate cases of rights and freedoms denied in Canada. In this sense, it is not only legitimate, but also strongly desirable in the Canadian education system.

Of course, our political landscape is also characterized by comprehensive doctrines that articulate a different vision for Canada's future, especially with the recent swell of neoliberalism. ${ }^{31}$ Some of our signature commitments as a nation are being redefined or eroded by policies based, not on neutrality, but on opposing views about justice. This underscores the point that we should not regard political values or traditions as unobjectionable simply because they have been endorsed by some politicians. Yet these views can often be shown to be at odds with other goals of the Canadian law and political system, which are more conducive to SJE.

An example of this type of conflict emerged in Ontario last year in the wake of Bill 13. The so-called "Accepting Schools Act" provides for protection against sexual harassment, gender-based violence, and homophobia, including allowing students to choose to form gay-straight alliances (GSAs). Some Catholic leaders, such as Cardinal Thomas Collins, complained that the bill undermines religious rights by forcing faith-based schools to allow students to describe and validate multiple sexual orientations in a way that chafes against scripture (O'Leary, 2012). Catholic schools-but not other faith-based schools-are funded by taxes in Ontario alongside the secular public system, and are generally entitled to teach the curriculum in a manner they deem consistent with the Catholic faith.

Here we have a situation of mutually exclusive comprehensive doctrines colliding under the auspices of an educational system that is supposed to avoid making pronouncements about the good. Putting aside the question of whether it is defensible for a liberal state to fund faith-based schools, ${ }^{32}$ the Government was in a position of having to choose between imposing a 
gay-positive bill on all schools equally and allowing Catholic schools to rely on their "Respecting Difference" document (Ontario Catholic School Trustees' Association, 2012). In other words, it had to affirm one comprehensive doctrine or another despite powerful dissent. ${ }^{33}$ Cardinal Collins even used liberal language to express the view that Catholic doctrines were being sidelined: "Why are Catholics not free to design their own methods of fighting bullying in harmony with the local situation and with their own particular school? ... We simply ask that diversity be respected in our society" (O'Leary, 2012).

Bill 13 may or may not be regarded as an instance of SJE (indeed, as a top-down measure it may by definition lack the subversiveness that some believe is integral to SJE), but it illustrates the kind of blending of political principles and exclusive ethical views that often surfaces in debates over SJE. When SJE is criticized for taking stances on social issues that are challenged by other powerful forces in the educational system, practitioners need to appeal to the higher-order values and laws that support it. Crucially, the atmosphere of anti-homophobia that Bill 13 seeks to create is not only consistent with values articulated at the level of the Charter, but also acknowledges the very risk of indoctrination that some critics of SJE have voiced. For if particular words and ways of identifying oneself are censored in some schools but not others, students may be arbitrarily denied the opportunity to learn about others' experiences and develop their own conception of the good life. ${ }^{34}$

\section{SOCIAL JUSTICE OR "BRAINWASHING"? SPLITTING THE HAIRS}

I am not prepared to suggest that there are universal rules about what forms of education can be defended philosophically, but in what follows I offer a list of criteria that seems to do most of the work needed to meet the brainwashing objection. This is not a definition of SJE; it is, rather, a list of conditions that all educational initiatives should live up to, SJE included. They cover both the form and the content of politicised educational endeavours, providing a guideline for discriminating between "brainwashing" and legitimate political messaging in schools. While their goal is to protect against indoctrination of any kind, it will be clear that they are generally more compatible with politically left-leaning views than with more conservative ones, thus corroborating the stereotype. Hence, while not all forms of so-called SJE are immune to charges of "brainwashing," and some forms of politicised education that are inconsistent with SJE are still legitimate, we can "split the hairs" in such a way that most SJE will be vindicated against the charges levelled in the Maclean's article and, moreover, be understood as reinforcing Canadian ideals.

Any comprehensive doctrines espoused in mandatory education in Canada must 
1) have legislative backing in the form of such documents as the Charter, human rights codes, and current policy

This criterion alone rules out most of the comprehensive doctrines that we would oppose in an educational setting. Keegstra's teachings are thus inadmissible, even if they were not (in addition) indoctrinative. It may be objected that existing legislation is inadequate or wrong-headed; this is addressed in (4) below.

The positions need not be backed by all documents: indeed, this type of education is a prime opportunity to reveal the inconsistencies-in the spirit if not the letter-between some of our laws and policies. Moreover, it is understood that laws have to be interpreted somehow, and there are more and less literal or metaphorical, traditional or progressive ways of interpreting them.

\section{2) be compatible with reasonable pluralism}

As we have seen, not all comprehensive doctrines accept the potential reasonableness of their rivals to the same extent. The view that abortion is evil is inherently unaccepting of the view that it is a personal choice, but not vice versa. It is therefore defensible to teach that abortion is a personal choice while acknowledging that some individuals and institutions condemn it, yet indefensible to teach, for example, the Catholic catechism as incontestable fact.

3) not engage in partisan politics or political activism that students do not choose

There is a critical difference between teaching students to think about the world in such a way that may motivate independent political involvement, and requiring students to defend or oppose particular political parties or policies. The issues debated by politicians should be analyzed in class, even when some positions are bound to emerge more strongly than others. But signing students up for rallies or marching them down to City Hall inhibits students from forming their own conclusions autonomously.

4) be connected with developing skills for democratic engagement

Elaborating on the preceding criterion, while comprehensive doctrines may be taught or endorsed, they should be accompanied by the development of age-appropriate skills such as critical thinking, logic, and media literacy that will help prevent any doctrines from becoming dogma and ensure lifelong reflection about substantive views, including those encompassed by law. Unlike Keegstra, who taught his students that mainstream views were conspiratorial and thus inured them pre-emptively against 
evidence, teachers should only teach views that they are willing to subject to scrutiny (Hare, 2001, pp. 248-249).

5) respect students' freedom to abstain from activities that contravene their own (emerging or tentative) comprehensive doctrines

When students do come to class with substantive commitments, these need to be respected. We now accept that it is profoundly objectionable to force a student to pray in school or to pledge allegiance to something she rejects. Likewise it is illiberal to force students to participate in social justice activities that they find repugnant, even if the activities are otherwise justified. This condition would not, however, require teachers to design alternative lesson plans or let students stay at home when topics such as sexual diversity are discussed. Students should be exposed to SJE, but entitled to hold their own opinions.

These conditions are not dissimilar from some articulations of SJE, such as Hackman's (2005): “[SJE] encourages students to take an active role in their own education and supports teachers in creating empowering, democratic, and critical educational environments" (p. 103). Yet this more general list of criteria can distinguish between defensible and indefensible applications of comprehensive doctrines and thus resist the logical claim that if SJE is allowed, religious fundamentalism or racist ideologies should be as well. In short, SJE is justifiable, not because every citizen endorses the concrete values it represents, but because and only insofar as it reflects a democratic political culture that does.

As a test of these principles, let me return to few examples of alleged SJE that were raised in the Maclean's article.

1. "first-graders brought home student planners marked with the international days of zero tolerance on female genital mutilation [FGM] and ending violence against sex workers." (Reynolds, 2012, p. 20)

Canada has strong legislative and cultural injunctions against genderbased violence and all forms of human rights violations (1). Bringing these issues to the attention of students in the school system, while difficult, can increase their understanding of current issues (4) without taking partisan stances on any policy positions (3). There is no concern about (2) or (5) because there is no protected space in Canadian society for endorsing these forms of violence. Whether first-graders are developmentally able to handle discussion of these issues is a different question. Age-appropriateness is presumed in all educational activities, not just SJE. In this case, with young children, (4) may be violated because they are not yet equipped to derive democratic skills from being taught about these phenomena. ${ }^{35}$ 
2. "the Durham Board of Education in Ontario came under fire for discouraging the terms 'wife' and 'husband' in class in favour of the gender-neutral 'spouse,' and the words 'boyfriend' and 'girlfriend' in favour of 'partner.' " (Reynolds, 2012, pp. 20-21)

Using gender-neutral terms such as "partner" is consistent with Canadian policy and liberal values, even though not everyone is comfortable with them. Changes in vocabulary may be initially awkward but ultimately help bring about social change, as evolutions in acceptable terms for women and people of colour over the last half-century demonstrate. The distinction needs to be preserved, however, between politically correct language and first-person authority. If students are punished for choosing to use more conventional terms to describe their own families or imagined relationships, criterion (5) would be violated.

3. "A Grade 3 class in Toronto took to the streets with signs and an oversized papier mâché oil pipeline to protest the laying of an actual pipeline in western Canada.” (Reynolds, 2012, p. 20)

This activity-regardless of the age of the students—violates (3), showing that what passes for (or is regarded as) SJE can tread too far in the direction of indoctrination. Yet there are appropriate ways of teaching about the effects of big oil without violating my criteria, and which may lead to students undertaking the same protest independently. For example, drawing attention to the negative impacts of the pipeline, such as its effects on the environment and on Aboriginal communities, is entirely justified by such laws as the Environmental Protection Act (1999) and recent social activism surrounding Aboriginal rights in Canada, particularly if accompanied by a critique of the political bias in media and government discussions of the issue, such as recent television ads promoting the tar sands. ${ }^{36}$

4. "OISE [The Ontario Institute for Studies in Education]'s website features a Grade 5 math lesson on government budgets that culminates in students writing letters to MPPs advocating changes in spending priorities. Though not explicitly partisan, it juxtaposes the money spent on the war in Afghanistan with the money spent on povertyand that does suggest a certain point of view." (Reynolds, 2012, p. 22)

Writing letters to MPPs on a given issue-whether the MPPs targeted are determined by the teacher or are up to the students-transgresses a fine line between democratic education and forced political engagement. Using government budgets to teach math is a great way to incorporate questions of justice into the curriculum, but presenting complex ethical questions as fact is manipulative. Students need to be given the skills and the opportunity to analyze the distribution of government resources 
(presumably outside of math class) and then choose whether to lobby for different spending priorities. ${ }^{37}$ The costs of war, both fiscal and otherwise, as well as the severity of poverty in Canada, can be underscored without forcing students to jump to policy conclusions.

As we can see, not every initiative that has been forwarded as an example of SJE will find full vindication within the criteria I have set out. This is not to say that the initiatives that fail my criteria are not examples of furthering social justice. Rather, they may be examples of social justice that cannot yet be defended coherently to the public at large, and therefore do not belong in the public education system. With greater social change, they may earn their defensibility in time. Likewise, these criteria may allow for philosophically defensible educational moves that social justice educators would balk at, although the most egregious ones have been ruled out. This is to be expected. Liberalism is fundamentally about getting along with people we disagree with.

I will conclude by anticipating one important criticism of my approach. It may be objected, especially from avid practitioners of SJE, that the space I have carved out for the defensible introduction of familiar, left-leaning social justice causes in K-12 is too narrow. After all, I am confining educational activities to overlap with the law. Is this not stagnant, conciliatory, or even antithetical to the very activist connotations of "social justice" I outlined earlier? What about the revolutionary function of education?

I have two responses to this concern. First, I maintain that there is ample space for progressive political education within the conditions I have laid out. Although SJE should be grounded to some extent in formal political commitments, there is often a substantial lag between the adoption of certain stances at a legal level and their actualization at a societal level. Indeed, laws and foundational state documents are aspirational: they declare what we believe in, not what is actually the case. Discrimination on the basis of sexual orientation is illegal in Canada, but homophobia is still rampant. If such prejudice were non-existent, presumably we would not need legislative efforts to curb its effects.

Much of the work of SJE lies in these interstices between ideals and practice-for example, in educating students so that they not only obey the law protecting same-sex couples from discrimination, but also come to understand and embrace anti-homophobia principles in their everyday lives. Progressive education has extensive work to do in protecting and furthering such values, and in reminding the Canadian public of its own stated commitment to equality. In addition, through its emphasis on democratic skill development, SJE can facilitate critiques of the law and encourage students to imagine more just social arrangements that we have yet to aspire to. The most progressive interpretations of the current law can give way to better laws in time.

Second, I am not ruling out the ethical view that it would be best, all else being equal, to radically educate all students-even indoctrinate 
them-into some of the values espoused by practitioners of SJE. Yet education also has an obligation, in a liberal democracy, to the public at large. The purpose and transformative potential of public education would be undermined if the curriculum were indeed susceptible to charges of "brainwashing." The business of changing social policy needs to be pursued in the public arena by autonomous adults. This does not mean, however, that education should be static or resigned. As Callan (1997) puts it, "[1]iberal democracy at its best, in education as in other social endeavours, will not leave everything as it is" (p. 13).

\section{ACKNOWLEDGMENTS}

For invaluable feedback on earlier drafts of this paper, I would like to thank Vida Panitch, Jordan DeCoste, three anonymous reviewers, and the editors of this journal.

\section{NOTES}

1. I take the informal term brainwashing used here to mean what educators and philosophers usually refer to as "indoctrination." Indoctrination is regarded as miseducative because it presents one, usually narrow and intolerant, view as being the only correct possible way of seeing the world. It can also be criticized particularly for interfering with the right of parents to inculcate their own values in their children, as is suggested in the Maclean's article (see also Callan, 2001). Throughout this article I will argue that SJE is necessarily guilty of neither charge.

2. Importantly, the Maclean's article conflates questions of age-appropriateness with general questions about what type of political messaging belongs in schools. In this article I will bracket the former, while acknowledging that it is bound up with the definition of brainwashing insofar as older students are less likely to uncritically imbibe their teachers' views.

3. Other defences or types of evidence could be offered, such as the claim that SJE leads to improved educational outcomes. However, there would still be a further philosophical question to answer about whether improved educational outcomes (whatever those are) justify the apparent abrogation of political neutrality in the common school system, as I discuss in the rest of this essay.

4. I will not attempt in this article to present any justification for SJE or politically loaded educational activities outside the Canadian context, as my argument is dependent on specific Canadian political traditions, policies and documents.

5. Note that my purpose here is broader than staking a claim in the debates over whether and how to raise controversial topics in the classroom (see, e.g., Hess, 2004), although controversy is of course essential here. SJE and the other forms of political education I am concerned with do not necessarily arise in discrete, nugget-sized topics with clearly opposed positions available (e.g., the morality of abortion), but are infused across the curriculum and may be pursued in 
highly subtle, even unconscious, ways, such as in the choice of texts or offhand comments. This exacerbates the concern over "indoctrination." Hence, although defending SJE may in some cases translate into defending teachers who take a conspicuous stance on a particular controversial issue (the oil sands, for example), I am not limiting my inquiry to such cases.

6. Other criteria may need to be added in certain cases. I am reluctant to label these exhaustive given the nearly infinite possible scenarios in which teachers may incorporate controversial beliefs into their teaching.

7. The expansion of sex education and critical study of religion are widely regarded as projects of left-leaning social justice educators, as I explain below.

8. Stevenson further argues that the meaning of ethical terms just is their emotive content, and that there are no moral facts and no ways of making moral arguments beyond emotional debate. I reject this meta-ethical view, but we can usefully adopt the term emotive without subscribing to it.

9. I will ultimately argue that the defence of SJE appeals to the status quo in terms of laws, national identity, and other aspirational sources for social organization, but criticizes the status quo in terms of how these ideals are presently realized.

10. For an alternate list of five principles of SJE, see Carlisle, Jackson, and George (2006).

11. These and other criteria for justice in the liberal state are most famously articulated by Rawls (1971).

12. Of course, the format that liberal societies have determined to be most conducive to such legitimacy is democracy, but democracy and liberalism are separable (Mouffe, 2000). For example, the electorate of a democracy could opt for highly illiberal governing principles, as emerging democracies in parts of the Middle East are demonstrating.

13. Rawls uses "reasonable" in a very technical sense to mean the willingness to participate in constructing fair political processes. Reasonable people "are ready to propose principles and standards as fair terms of cooperation and to abide by them willingly, given the assurance that others will likewise do so. Those norms they view as reasonable for everyone to accept and therefore as justified to them; and they are ready to discuss the fair terms that others propose" (Rawls, 1993, p. 49). In his earlier work, A Theory of Justice (1971). Rawls spells out a substantive theory of fair political processes, which he calls "justice as fairness."

14. The extent to which Rawls changed his views between 1971 and 1993 is contentious among political philosophers (e.g., Waldron, 2004). Although he repudiated comprehensive liberalism in his later work, some philosophers still view him as a veiled comprehensive liberal. It is not my purpose here to take a position on this debate.

15. Rawls (1993) expresses hesitation about using the term neutral in his discussion of political liberalism, explaining that " $[\mathrm{j}]$ ustice as fairness is not procedurally neutral ... its principles of justice are substantive and express far more than 
procedural values ..." (p. 192). It is statements such as this that give fodder to the interpretation that Rawls is himself a comprehensive liberal. Yet in the same section, he argues for political liberalism as "neutrality of aim" (p. 192) in the sense that "the state is not to do anything intended to favour or promote any particular comprehensive doctrine rather than another, or to give greater assistance to those who pursue it" (p. 193). Although neutrality of aim "is not to be confused with neutrality of effect or influence," these latter effects of state actions are supposed to be unintentional. As I will argue later, there are situations in which it is impossible for the state to avoid intentionally favouring certain particular comprehensive doctrines over others, and the same is true for educators.

16. "Political virtues" are defined in reference to Rawls's theory of justice as fairness. They include "the virtues of fair social cooperation such as the virtues of civility and tolerance, of reasonableness, and the sense of fairness" (Rawls, 1993, p. 194).

17. For the purposes of this article, I leave aside the question of how, absent overlapping consensus, such a state position is legitimated.

18. "Reasonable persons," Rawls (1993) argues, "will think it unreasonable to use political power, should they possess it, to repress comprehensive views that are not unreasonable, though different from their own" (p. 60). That is, they will hold liberal beliefs about political arrangements. Reasonableness and liberalism are defined with reference to one another.

19. While remaining as generous as possible in his definition of "reasonableness," Rawls affirms this conclusion. Rawls's (1993, p. 59) overlapping consensus is not intended to include or satisfy unreasonable citizens.

20. Rawls himself emphasizes the need for the state to extend the means to all citizens to achieve freedom and equality. His theory of justice as fairness (1971), which elaborates basic ideas of distributive justice and access to resources, supports this conception. Regardless of whether Rawls is properly understood as a comprehensive liberal, I wish to endorse comprehensive liberalism as the more persuasive, and, in fact, actual Canadian, version of the theory.

21. The Maclean's article focuses exclusively on students in elementary school. I am sidestepping the question of when children stop being children on the assumption that there is a blurry continuum of development that each child proceeds through at her own pace.

22. Using Hess's four types of responses to controversial issues in the classroom, a strictly political liberal would endorse either "avoidance" ("The issue is controversial, but ... I do not think I can teach it fairly") or "balance" ("The issue is controversial and ... I will try to ensure that various positions get a best case, fair hearing") (Hess, 2004, p. 259). The political liberal would further have to argue that there is relatively little implicit bias in educational choices that do not directly engage with recognizably controversial issues.

23. Kant (1803/2007) makes an argument to this effect in his Lectures on Pedagogyfirst children must be taught what is moral, then they can learn to see it for themselves. 
24. Referring to Hess again, the response here would be that (1) controversial messages are imparted in education even when there is no conspicuous introduction of a controversial issue (e.g., abortion) in the classroom, and (2) it is not illegitimate in some cases for teachers to adopt the "privilege" approach ("It is controversial, but I think there is a clearly right answer and will try to get my students to adopt that position") (Hess, 2004, p. 259).

25. Keegstra was an Alberta teacher who was censured for attempting to indoctrinate his students into extreme racist views. See Hare, 2001.

26. To some advocates of SJE, its cross-curricular (or super-curricular) nature is paramount. The fact that oppression and inequality are pervasive means that questions of social justice need to be tackled everywhere, not reserved for courses dedicated to politics or controversial issues. This is no doubt one of the complaints of detractors.

27. Bill C-279, which would protect "gender identity and gender expression" under the Criminal Code, was introduced on September 21, 2011, was deferred most recently on June 25, 2013. There remains controversy over the appropriate way to protect transgender people in federal law, and of course transgender individuals are still severely discriminated against in many systemic and explicit ways. My point is not to suggest that we have completed our work in protecting people of all sex/gender identities, but rather that there is some official commitment to inclusion and anti-oppression, which is more than many stateseven liberal ones-have done. I return to this gap between legislation and reality in the conclusion.

28. Once again, I am not suggesting that such programs are adequate, particularly as they are under extreme assault at the moment. Instead, I am pointing to elements of Canada's political culture that demonstrate a more comprehensive liberalism than what Rawls (1993) strictly requires.

29. This is more or less what Rawls means by "egalitarian liberalism." See Sandel, 1998, pp. 184-185.

30. In Canada, as in the United States, the legal right to access abortion is undermined in many ways by additional laws, restrictions, and a dearth of clinics in many regions. For example, there is currently no abortion provider in the province of Prince Edward Island. This constitutes a mismatch between the substantive stance taken by the government and the reality for many Canadians, which in fact helps define the work of SJE, as I argue below.

31. Neoliberalism is rightly considered a species of liberalism, but one that does not graft neatly onto the political/comprehensive divide I have been discussing. Rather, it is an outgrowth of what McDonough and Feinberg (2003) call "classical liberalism," which believes in the maximization of liberty through small government and unrestricted markets, as opposed to "contemporary liberalism," described above. Neoliberalism is not less comprehensive than contemporary liberalism, but proceeds from different views about justice.

32. Many critics such as the Canadian Civil Liberties Association and the United Nations Human Rights Committee have decried Canada's selective funding of Catholic schools to the exclusion of other faith-based schools, which is protected in the Constitution. However, this issue is actually tangential to my point. 
In a liberal state, it seems unjustified to allow religious schools, whether government-funded or not, to teach exclusionary doctrines. All schools that grant common degrees should be subject to the same standards of inclusiveness and consistency with Canadian law.

33. This is an example of the failure of Rawls's ideal of "neutrality of aim."

34. This risk is of course in addition to the more immediate risk of homophobic bullying and personal distress arising from developing one's sexual identity an anti-gay environment.

35. It is possible that these awareness days were also objected to on the grounds that students may hail from countries or cultures where such violence is accepted; there may even be girls in the class who have undergone FGM. This "cultural relativism" concern is ruled out on the version of liberalism I have espoused. There is no place in Canada, much less the education system, to talk about FGM as a reasonable culture practice that happens to differ from others that are more common in Canada. Personal experiences of violence, as well as distress over conflicting messages between school and home, need to be dealt with sensitively, but validating FGM so as to "include" these cultures is not consistent with Canadian, or any liberal, values.

36. These activities would probably fall flat with students in a Grade 3 classroom, suggesting that opposition to the protest was likely also based on concerns about age-appropriateness (indeed, what counts as indoctrination among young children may not count as such among older students with more developed critical-thinking skills). Based on my criteria, the mandatory protest of the oil pipeline is not a legitimate activity at any grade level, but older students, such as those in Grades 7 to 12 , could benefit from an exploration of the politics of the pipeline.

37. In a civics class, it would be appropriate to assign students the task of choosing a political issue and writing a letter about it to an MPP of their choice, because this encourages democratic participation and political development without forcing students into a particular partisan stance.

\section{REFERENCES}

Apple, M. (2009). Some ideas on interrupting the right: On doing critical educational work in conservative times. Education, Citizenship and Social Justice, 4(2), 87-101.

Bell, L. A. (1997). Theoretical foundations for social justice education. In M. Adams, L. A. Bell, \& P. Griffin (Eds.), Teaching for diversity and social justice: A sourcebook (pp. 3-15). New York: Routledge.

Berlin, I. (1969). Two concepts of liberty. In Four essays on liberty (pp. 118-172). Oxford, UK: Oxford University Press.

Bull, B. (2008). Social justice in education: An introduction. New York: Palgrave Macmillan.

Bull, B. (2009). Policy implications of social justice in education. Ethics and Education, 4(2), 141-152.

Callan, E. (1997). Creating citizens: Political education and liberal democracy. Oxford, UK: Oxford University Press. 
Callan, E. (2001). Indoctrination and parental rights. In W. Hare \& J. Portelli (Eds.), Philosophy of education: Introductory readings (rev. $3^{\text {rd }}$ ed., pp. 121-130). Calgary, AB: Detselig.

Carlisle, L. R., Jackson, B. W., \& George, A. (2006). Principles of social justice education: The Social Justice Education in Schools Project. Equity E Excellence in Education, 39(1), 55-64.

Dworkin, R. (1978). Liberalism. In S. Hampshire (Ed.), Public and private morality (pp.113-143). Cambridge, UK: Cambridge University Press.

Gaus, G. F. (2003). Contemporary theories of liberalism: Public reason as a postEnlightenment project. London: Sage.

Gaus, G. F. (2004). The diversity of comprehensive liberalisms. In G. F. Gaus \& C. Kukathas (Eds.), The handbook of political theory (pp. 100-114). London: Sage.

Gewirtz, S. (2006). Towards a contextualized analysis of social justice in education. Educational Philosophy and Theory, 38(1), 69-81.

Grimaldi, E. (2012). Neoliberalism and the marginalisation of social justice: The making of an education policy to combat social exclusion. International Journal of Inclusive Education, 16(11), 1131-1154.

Gutmann, A. (1987). Democratic education. Princeton, NJ: Princeton University Press.

Gutmann, A. (1995). Civic education and social diversity. Ethics, 105(3), 557-579.

Hackman, H. (2005). Five essential components for social justice education. Equity and Excellence in Education, 38(2), 103-109.

Hare, W. (2001). Propaganda in the classroom: The Keegstra case. In W. Hare \& J. Portelli (Eds.), Philosophy of education: Introductory readings (rev. $3^{\text {rd }}$ ed., pp. 243-258). Calgary, AB: Detselig.

Hess, D. E. (2004). Controversies about controversial issues in democratic education. PSOnline. Retrieved November 1, 2013, from www.apsanet.org

Hytten, K., \& Bettez, S. C. (2011). Understanding education for social justice. Educational Foundations, 25(1-2), 7-24.

Kant, I. (2007). Lectures on pedagogy. In G. Zöller \& R. B. Louden (Eds.), Anthropology, history and education (pp. 437-485). Cambridge, UK: Cambridge University Press. (Original work published 1803)

Kozol, J. (2005). The shame of the nation: The restoration of apartheid schooling in America. New York: Crown.

Larmore, C. (1990). Political liberalism. Political Theory, 18(3), 339-360.

Lipman, P. (2007). "No Child Left Behind": Globalization, privatization, and the politics of inequality. In E. W. Ross \& R. Gibson (Eds.), Neoliberalism and education reform (pp. 35-58). Cresskill, NJ: Hampton Press.

McDonough, K., \& Feinberg, W. (Eds.). (2003). Citizenship and education in liberal democratic societies: Teaching for cosmopolitan values and collective identities. Oxford, UK: Oxford University Press.

Mouffe, C. (2000). The democratic paradox. London: Verso.

Murrell, P. Jr. (2006). Toward social justice in urban education: A model of collaborative cultural inquiry in urban schools. Equity $\mathcal{E}^{2}$ Excellence in Education, 39(1), 81-90.

Neufeld, B., \& Davis, G. (2010). Civic respect, civic education, and the family. Educational Philosophy and Theory, 42(1), 94-111.

Nussbaum, M. (2011). Perfectionist liberalism and political liberalism. Philosophy and Public Affairs, 39(1), 3-45.

O’Leary, J. (2012, June 1). Cardinal Collins defends Catholic approach to bullying. The Catholic Register. Retrieved November 12, 2013, from http:/ /www .catholicregister.org/component/k2/item/14577-cardinal-collins-defends-non -gsa-approach-to-school-bullying 
Ontario Catholic School Trustees' Association. (2012, June 25). Respecting difference. A resource for Catholic schools in the Province of Ontario. Ottawa, ON: Author.

Ontario Ministry of Education. (2009). Ontario's equity and inclusive education strategy. Toronto, ON: Author.

Rawls, J. (1971). A theory of justice. Cambridge, MA: Harvard University Press.

Rawls, J. (1985). Justice as fairness: Political not metaphysical. Philosophy and Public Affairs, 14(3), 223-252.

Rawls, J. (1993). Political liberalism. New York: Columbia University Press.

Raz, J. (1986). The morality of freedom. Oxford, UK: Clarendon Press.

Reynolds, C. (2012, November 5). Why are schools brainwashing our children? Maclean's, 125(43), 20-23.

Saltman, K. (2006). The right-wing attack on critical and public education in the United States: From neoliberalism to neoconservativism. Cultural Politics, 2(3), 339-358.

Sandel, M. (1998). Liberalism and the limits of justice ( $2^{\text {nd }}$ ed.). Cambridge, UK: Cambridge University Press.

Sensoy, Ö., \& DiAngelo, R. (2012). Is everyone really equal? An introduction to key concepts in social justice education. New York: Teachers College Press.

Taylor, C. (2003). Cross-purposes: The liberal-communitarian debate. In D. Matravers \& J. Pike (Eds.), Debates in contemporary political philosophy: An anthology (pp. 195-212). London: Routledge.

Ukpokodu, O. N. (2010). Imperatives for social justice in teacher education. Teacher Education and Practice, 23(4), 488-491.

Waldron, J. (1987). Theoretical foundations of liberalism. The Philosophical Quarterly, 37(147), 127-150.

Waldron, J. (2004). Liberalism, political and comprehensive. In G. F. Gaus \& C. Kukathas (Eds.), The handbook of political theory (pp. 89-100). London: Sage.

Warnick, B. R. (2012). Rethinking education for autonomy in pluralistic societies. Educational Theory, 62(4), 411-426.

Wise, A. E. (2006, June 6). Accreditation hearing of the National Council for Accreditation of Teacher Education (NCATE) before the U.S. Department of Education's National Advisory Committee on Institutional Quality and Integrity (NACIQI). Washington, DC: Government Printing Office.

Wolterstorff, N. (1997). Why we should reject what liberalism tells us about speaking and acting in public for religious reasons. In P. Weithman (Ed.), Religion and contemporary liberalism (pp. 162-181). Notre Dame, IN: Notre Dame University Press.

Zajda, J., Majhanovich, S., \& Rust, V. (2006). Introduction: Education and social justice. Review of Education, 52(1-2), 9-22. 